\title{
Fracturing Pressure of Shallow Sediment in Deep Water Drilling
}

\author{
Chuanliang Yan, Jingen Deng, Lianbo Hu, and Baohua Yu \\ State Key Lab of Petroleum Resources and Prospecting, China University of Petroleum, Beijing 102249, China \\ Correspondence should be addressed to Jingen Deng; dengjingen@126.com
}

Received 22 March 2013; Revised 3 July 2013; Accepted 4 July 2013

Academic Editor: Irene Penesis

Copyright (C) 2013 Chuanliang Yan et al. This is an open access article distributed under the Creative Commons Attribution License, which permits unrestricted use, distribution, and reproduction in any medium, provided the original work is properly cited.

\begin{abstract}
The shallow sediment in deep water has weak strength and easily gets into plastic state under stress concentration induced by oil and gas drilling. During drilling, the formation around a wellbore can be divided into elastic zone and plastic zone. The unified strength theory was used after yielding. The radius of the plastic zone and the theoretical solution of the stress distribution in these two zones were derived in undrained condition. The calculation model of excess pore pressure induced by drilling was obtained with the introduction of Henkel's excess pore pressure theory. Combined with hydraulic fracturing theory, the fracturing mechanism of shallow sediment was analyzed and the theoretical formula of fracturing pressure was given. Furthermore, the influence of the parameters of unified strength theory on fracturing pressure was analyzed. The theoretical calculation results agreed with measured results approximately, which preliminary verifies the reliability of this theory.
\end{abstract}

\section{Introduction}

With substantial exploration, the oil and gas resources on land and shallow water field cannot meet the need of the development of industry. Recently, more than $40 \%$ of the newly proved oil and gas resources are found in deep water field, which is much more difficult to develop [1]. Exploring and developing oil and gas in deep water field are one of the important developing trends of oil and gas industry.

Maintaining wellbore stability is an important issue in oil and gas industry. In the process of drilling, the economic losses caused by wellbore instability reach more than one billion dollar every year [2], and the lost time is accounting for over $40 \%$ of all drilling related nonproductive time [3]. For deep water drilling, the overburden pressure and fracturing pressure are lower than that on land, so the risk of wellbore instability is much higher [4]. The conventional calculation models of fracturing pressure are based on the elastic mechanics [5-9]. However, in some cases, the formation experiences plastic before the fracture initiates. Aadnøy and Belayneh [10] established an elastic-plastic model for the calculation of fracturing pressure with the consideration of the plastic zone around a wellbore. According to his theory, the fracture initiates at the interface of the elastic zone and the plastic zone, which leads to the calculation result much higher than that of the elastic model and disagrees with the fact that the fracturing pressure of shallow sediment in deep water is low. For deep water drilling, researchers mostly analyze the fracturing pressure based on the elastic model or empirical model based on the field testing data [11-15]; this may be suitable for the deep and hard layer but cannot be applied to the shallow sediment in deep water, which is unconsolidated, subjected to the consolidation theory of saturated soil, and experiences plastic before fracturing [ 1 , $16,17]$. The traditional models cannot reveal its fracturing mechanism. Although some researchers have done research on the fracturing pressure of shallow sediment in deep water specially $[1,16,18-20]$, these models are empirical or semiempirical models based on the field testing data and they are not based on the stress state around the wellbore and thus cannot explain the fracturing mechanism of shallow sediment in deep water. The traditional wellbore stability analysis is set up on the basis of rock mechanics engineering. Excess pore pressure theory [21] in soil mechanics will be adopted in this paper. Formations around the wellbore are divided into elastic zone and plastic zone. The formation in plastic zone obeys the unified strength theory. Considering the excess pore pressure due to soil squeezing effect induced by wellbore column pressure, combined with hydraulic fracturing theory to research the fracturing mechanism of shallow sediment 
in deep water. Assuming that tensile stress will appear when the pore pressure is greater than the combination of the insitu stress and the increment of stress due to drilling. The fracturing pressure is defined as the wellbore column pressure when the tensile stress exceeds the tensile strength of the formation when the fracture initiates.

\section{Mechanical Model and Basic Hypothesis}

The shallow sediment in deep water can be treated as homogeneous and isotropic ideal elastoplastic material [16, 22-24]. The sediment is in elastic state before drilling and obeys the unified strength theory after yielding. Shallow sediment in deep water experienced short deposition time and little tectonic movement, and the Poisson's ratio is large, so the difference of the horizontal stresses is very small. It is reasonable to assume that the horizontal in-situ stress of shallow sediment in deep water is uniform $[16,20]$.

The formation around the wellbore is subjected to the in-situ stress and the drilling fluid column pressure. The stress field around the wellbore redistributes and stress concentration occurs while drilling. When the stress state around the wellbore exceeds the elastic limitation, the near wellbore formation will turn into plastic state, while the formation beyond the plastic zone will still remain elastic. The mechanical model of a wellbore is shown in Figure 1.

As shown in Figure 1, $\sigma_{h}$ is the far-field horizontal in-situ stress; $P_{p 0}$ is the original pore pressure; $P_{p}$ is the pore pressure after drilling; $P_{w}$ is the wellbore pressure; $r_{w}$ is the wellbore radius; $r_{p}$ is the radius of the elastic-plastic zone interface, so the plastic zone is within the radius of $r_{p}$; the formation which is outside of the radius $r_{p}$ is still in elastic state.

The unified strength theory was proposed by $\mathrm{Yu}$ and $\mathrm{He}$ in 1991 [25]. This theory has clear physical concepts and simple mathematical formula and agrees with experimental results greatly, and it performed well in various engineering all over the world [26-29]. This theory is based on the physical model of twin shear stress element. This theory not only takes into consideration the different influence of shear stress and the normal stress on the yielding and failure of materials but also the influence of intermediate principle stress in different stress state. So this theory can be applied to a large range of materials from metal to rock material. When $\varphi$ and $C$ stand for internal friction angel and cohesive, respectively, the unified strength theory can be written as

$$
\begin{aligned}
\sigma_{1}= & \frac{2(1+b)(1+\sin \varphi)+m b(\sin \varphi-1)}{[2(1+b)-m b](1-\sin \varphi)} \sigma_{3} \\
& +\frac{4(1+b) C \cos \varphi}{[2(1+b)-m b](1-\sin \varphi)},
\end{aligned}
$$

where $b(0 \leq b \leq 1)$ reveals the influence of intermediate principle stress on the yielding and failure of materials. It is the parameter that reveals the influence of the intermediate stress and different strength criterions: when $b=0$, (1) is Mohr-Coulomb strength criterion; when $b=1$, the formula is twin shear strength criterion. $m$ is the coefficient of intermediate stress whose physical meaning can be seen in

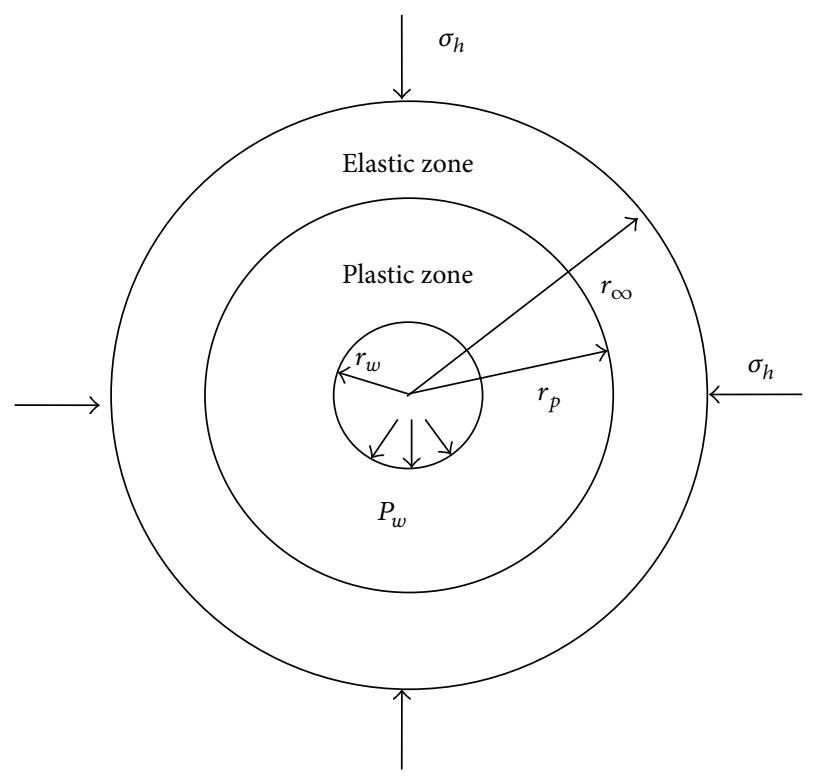

FIGURE 1: The mechanical model of a wellbore.

Yu Maohong's research [30]. For plane strain state, $m \leq 1$; in elastic state, $m<1$; in plastic state, $m$ approaches 1 ; in this paper, $m$ is assumed to be 1 when the shallow sediment is in plastic state. $C, \varphi$ are the sediment cohesion and internal friction angle in undrained condition, respectively; this paper uses the total stress shear strength parameters [31, 32].

For wellbore wall fracturing problem while drilling, it is always to be true that $[9,13] \sigma_{r}=\sigma_{1}$ and $\sigma_{\theta}=\sigma_{3}$; the intermediate stress is presented as follows $[13,33-36]$ :

$$
\sigma_{z}=\sigma_{2}=\frac{m\left(\sigma_{1}+\sigma_{3}\right)}{2} .
$$

According to the unified strength theory, the yielding function of shallow sediment in deep water before fracturing can be expressed as follows:

$$
\sigma_{r}=M \sigma_{\theta}+\sigma_{0}
$$

in which

$$
\begin{gathered}
M=\frac{2(1+b)(1+\sin \varphi)+m b(\sin \varphi-1)}{[2(1+b)-m b](1-\sin \varphi)}, \\
\sigma_{0}=\frac{4(1+b) C \cos \varphi}{[2(1+b)-m b](1-\sin \varphi)} .
\end{gathered}
$$

In the drilling process, a tight layer of mud cake will generate on the wellbore wall which can prevent the seepage of the fluid between the wellbore and the formation. So it is reasonable to assume that the shallow sediment is in untrained condition while drilling. The stress state around the wellbore will change due to drilling; under the undrained condition, part of the stress will be taken by the pore fluid, so the pore pressure will change after drilling. The change of the pore pressure caused by drilling is defined as excess 
pore pressure, marked with $\Delta P$ and expressed in the following equation:

$$
\Delta P=P_{p}-P_{p 0}
$$

\section{Fracturing Pressure of Shallow Sediment in Deep Water}

3.1. Elastic-Plastic Analysis around the Wellbore. According to the stress balance formula, the stress relationship at any point in the shallow sediment while drilling can be expressed as follows:

$$
\frac{d \sigma_{r}}{d r}+\frac{\sigma_{r}-\sigma_{\theta}}{r}=0
$$

where $\sigma_{r}$ and $\sigma_{\theta}$ are the radial stress, and tangential stress respectively.

In the elastic zone, according to the axial symmetry problems solution and boundary conditions: $\left.\sigma_{r}\right|_{r=r_{p}}=$ $\sigma_{r p}, \lim _{r \rightarrow \infty} \sigma_{r}=\sigma_{h}$, the near wellbore stress in the elastic zone is given by the following [37]:

$$
\begin{gathered}
\sigma_{r}=\sigma_{h}-\left(\sigma_{h}-\sigma_{r p}\right) \frac{r_{p}^{2}}{r^{2}}, \\
\sigma_{z}=\sigma_{v}, \\
\sigma_{\theta}=\sigma_{h}+\left(\sigma_{h}-\sigma_{r p}\right) \frac{r_{p}^{2}}{r^{2}},
\end{gathered}
$$

where $\sigma_{r p}$ is the radial stress at the interface of the plastic zone and the elastic zone.

Combining (3) and (6) and using the boundary condition $\left.\sigma_{r}\right|_{r=r_{w}}=P_{w}$, the stress field in the plastic zone can be deduced and written as follows:

$$
\begin{gathered}
\sigma_{r}=\left(P_{w}+\frac{\sigma_{0}}{M-1}\right)\left(\frac{r_{w}}{r}\right)^{(M-1) / M}-\frac{\sigma_{0}}{M-1}, \\
\sigma_{z}=\frac{M+1}{2 M}\left(P_{w}+\frac{\sigma_{0}}{M-1}\right)\left(\frac{r_{w}}{r}\right)^{(M-1) / M}-\frac{\sigma_{0}}{M-1}, \\
\sigma_{\theta}=\frac{1}{M}\left(P_{w}+\frac{\sigma_{0}}{M-1}\right)\left(\frac{r_{w}}{r}\right)^{(M-1) / M}-\frac{\sigma_{0}}{M-1} .
\end{gathered}
$$

According to the continuity of the stress, the stress at the elastic-plastic interface should agree with both (7) and (8). So the radius of the plastic zone can be written as follows:

$$
r_{p}=r_{w}\left[\frac{(M+1)\left[(M-1) P_{w}+\sigma_{0}\right]}{2 M\left[(M-1) \sigma_{h}+\sigma_{0}\right]}\right]^{M /(M-1)} \text {. }
$$

The stresses at the elastic-plastic interface are

$$
\begin{gathered}
\sigma_{r p}=\frac{2 M \sigma_{h}+\sigma_{0}}{M+1}, \\
\sigma_{\theta p}=\frac{2 \sigma_{h}-\sigma_{0}}{M+1} .
\end{gathered}
$$

TABLE 1: The experience value of $A[40]$.

\begin{tabular}{lc}
\hline Soil type (saturated) & $A$ \\
\hline Loose fine sand & $2 \sim 3$ \\
Sensitive clay & $0.75 \sim 1.5$ \\
Normally consolidated clay & $0.5 \sim 1.0$ \\
Mildly consolidated clay & $0 \sim 0.5$ \\
Seriously consolidated clay & $-0.5 \sim 0$ \\
\hline
\end{tabular}

Inserting (9) and (10) into (7), the final stress solutions in the elastic zone can be written as

$$
\begin{aligned}
\sigma_{r}= & \sigma_{h}-\frac{(1-M) \sigma_{h}-\sigma_{0}}{M+1} \frac{r_{w}^{2}}{r^{2}} \\
& \times\left[\frac{(M+1)\left[(M-1) P_{w}+\sigma_{0}\right]}{2 M\left[(M-1) \sigma_{h}+\sigma_{0}\right]}\right]^{2 M /(M-1)}, \\
\sigma_{\theta}= & \sigma_{h}+\frac{(1-M) \sigma_{h}-\sigma_{0}}{M+1} \frac{r_{w}^{2}}{r^{2}} \\
& \times\left[\frac{(M+1)\left[(M-1) P_{w}+\sigma_{0}\right]}{2 M\left[(M-1) \sigma_{h}+\sigma_{0}\right]}\right]^{2 M /(M-1)} .
\end{aligned}
$$

3.2. Solution of Excess Pore Pressure. Saturated soil is composed of solid particle skeleton and pores full of water. When imposed upon by an external force, the force will be balanced by both pore pressure and effective stress; the pore pressure increment induced by external load is called "excess pore pressure" [21]. Drilling will result in stress concentration around the wellbore; under the undrained condition, it will cause the change of pore pressure. At present, the solution of excess pore pressure is based on the research of Skempton and Henkel [38]. Skempton [39] established the calculation formula of excess pore pressure based on the experimental research of conventional triaxial tests of the soil:

$$
\Delta P=B\left[\Delta \sigma_{3}+A\left(\Delta \sigma_{1}-\Delta \sigma_{3}\right)\right]
$$

where $B$ is the Skempton's pore pressure parameter under the acting of both isotropic stress and deviatoric stress, and it is related to the soil saturation, for saturated soil, $B=1.0 ; A$ is the Skempton's pore pressure parameter under the acting of deviatoric stress, which can be determined by experiment or experience (as shown in Table 1). $\Delta \sigma_{1}$ and $\Delta \sigma_{3}$ stand for the maximum and the minimum principal stress increments, respectively.

Henkel [41] reasoned that under complex stress condition, the calculation of excess pore pressure should take the influence of the intermediate principle stress into consideration. The excess pore pressure under triaxial stress condition consists of two parts: one part caused by mean normal stress and the other part caused by mean shear stress. He put forward the following calculation formulas:

$$
\Delta P=\beta \Delta \sigma_{\mathrm{oct}}+\alpha \Delta \tau_{\mathrm{oct}}
$$


in which

$$
\begin{gathered}
\Delta \sigma_{\mathrm{oct}}=\frac{1}{3}\left(\Delta \sigma_{1}+\Delta \sigma_{2}+\Delta \sigma_{3}\right) \\
\Delta \tau_{\mathrm{oct}}=\frac{1}{3} \sqrt{\left(\Delta \sigma_{1}-\Delta \sigma_{2}\right)^{2}+\left(\Delta \sigma_{2}-\Delta \sigma_{3}\right)^{2}+\left(\Delta \sigma_{3}-\Delta \sigma_{1}\right)^{2}}
\end{gathered}
$$

where $\alpha$ and $\beta$ are the Henkel's pore pressure coefficients. For saturated soil, $\beta=1$.

In conventional triaxial tests, it has the relationship $\Delta \sigma_{2}=$ $\Delta \sigma_{3}$. Inserting it to the Henkel's excess pore pressure formula, the following formula is available:

$$
\Delta P=\Delta \sigma_{3}+\frac{(1+\alpha \sqrt{2})\left(\Delta \sigma_{1}-\Delta \sigma_{3}\right)}{3}
$$

Compared with Skempton's formula, Henkel's excess pore pressure formula can be rewritten as follows:

$$
\begin{aligned}
\Delta P & =\beta \Delta \sigma_{\mathrm{oct}}+\frac{(3 A-1) \Delta \tau_{\mathrm{oct}}}{\sqrt{2}} \\
& \approx \beta \Delta \sigma_{\mathrm{oct}}+(2.12 A-0.71) \Delta \tau_{\mathrm{oct}} .
\end{aligned}
$$

According to (8), the stress increment in the plastic zone induced by drilling is expressed as follows:

$$
\begin{gathered}
\Delta \sigma_{r}=\left(P_{w}+\frac{\sigma_{0}}{M-1}\right)\left(\frac{r_{w}}{r}\right)^{(M-1) / M}-\frac{\sigma_{0}}{M-1}-\sigma_{h}, \\
\Delta \sigma_{z}=\frac{M+1}{2 M}\left(P_{w}+\frac{\sigma_{0}}{M-1}\right)\left(\frac{r_{w}}{r}\right)^{(M-1) / M}-\frac{\sigma_{0}}{M-1}-\sigma_{h} \\
\Delta \sigma_{\theta}=\frac{1}{M}\left(P_{w}+\frac{\sigma_{0}}{M-1}\right)\left(\frac{r_{w}}{r}\right)^{(M-1) / M}-\frac{\sigma_{0}}{M-1}-\sigma_{h} .
\end{gathered}
$$

Calculating the mean normal stress increment $\Delta \sigma_{\text {oct }}$ and the mean shear stress increment $\Delta \tau_{\text {oct }}$ based on (17) and then inserting them into (16), the excess pore pressure in the plastic zone will be obtained by Henkel's excess pore pressure formula:

$$
\begin{aligned}
\Delta P= & \frac{(1.73 A+0.42)(M-1)+2}{2 M}\left(P_{w}+\frac{\sigma_{0}}{M-1}\right)\left(\frac{r_{w}}{r}\right)^{(M-1) / M} \\
& -\frac{\sigma_{0}}{M-1}-\sigma_{h} .
\end{aligned}
$$

The principle stress increment in the elastic zone can be deduced based on the stress distribution equation (11). One has

$$
\begin{aligned}
\Delta \sigma_{r}= & -\frac{(1-M) \sigma_{h}-\sigma_{0}}{M+1} \frac{r_{w}^{2}}{r^{2}} \\
& \times\left[\frac{(M+1)\left[(M-1) P_{w}+\sigma_{0}\right]}{2 M\left[(M-1) \sigma_{h}+\sigma_{0}\right]}\right]^{2 M /(M-1)}, \\
\Delta \sigma_{z}=0, & \\
\Delta \sigma_{\theta}= & \frac{(1-M) \sigma_{h}-\sigma_{0}}{M+1} \frac{r_{w}^{2}}{r^{2}} \\
& \times\left[\frac{(M+1)\left[(M-1) P_{w}+\sigma_{0}\right]}{2 M\left[(M-1) \sigma_{h}+\sigma_{0}\right]}\right]^{2 M /(M-1)}
\end{aligned}
$$

The excess pore pressure in the elastic zone calculated by Henkel's excess pore pressure formula can be written as

$$
\begin{aligned}
\Delta P= & \frac{(0.58-1.73 A)\left[(1-M) \sigma_{h}-\sigma_{0}\right]}{M+1} \frac{r_{w}^{2}}{r^{2}} \\
& \times\left[\frac{(M+1)\left[(M-1) P_{w}+\sigma_{0}\right]}{2 M\left[(M-1) \sigma_{h}+\sigma_{0}\right]}\right]^{2 M /(M-1)}
\end{aligned}
$$

3.3. Effective Stress around the Wellbore. According to Terzaghi's effective stress principle, the effective stress in the plastic zone can be written as follows:

$$
\begin{aligned}
\sigma_{r}^{\prime}= & \sigma_{r}-\Delta P-P_{p 0} \\
= & \frac{(1.58-1.73 A)(M-1)}{2 M}\left(P_{w}+\frac{\sigma_{0}}{M-1}\right)\left(\frac{r_{w}}{r}\right)^{(M-1) / M} \\
& +\sigma_{h}-P_{p 0}, \\
\sigma_{\theta}^{\prime}= & \sigma_{\theta}-\Delta P-P_{p 0} \\
= & \frac{-(1.73 A+0.42)(M-1)}{2 M}\left(P_{w}+\frac{\sigma_{0}}{M-1}\right)\left(\frac{r_{w}}{r}\right)^{(M-1) / M} \\
& +\sigma_{h}-P_{p 0}, \\
\sigma_{z}^{\prime}= & \sigma_{z}-\Delta P-P_{p 0} \\
= & \frac{(0.58-1.73 A)(M-1)}{2 M}\left(P_{w}+\frac{\sigma_{0}}{M-1}\right)\left(\frac{r_{w}}{r}\right)^{(M-1) / M} \\
& +\sigma_{h}-P_{p 0} .
\end{aligned}
$$


The effective stress in the elastic zone can be written as

$$
\begin{aligned}
\sigma_{r}^{\prime}= & \sigma_{h}-\frac{(1.58-1.73 A)\left[(1-M) \sigma_{h}-\sigma_{0}\right]}{M+1} \frac{r_{w}^{2}}{r^{2}} \\
& \times\left[\frac{(M+1)\left[(M-1) P_{w}+\sigma_{0}\right]}{2 M\left[(M-1) \sigma_{h}+\sigma_{0}\right]}\right]^{2 M /(M-1)}-P_{p 0}, \\
\sigma_{\theta}^{\prime}= & \sigma_{h}+\frac{(0.42+1.73 A)\left[(1-M) \sigma_{h}-\sigma_{0}\right]}{M+1} \frac{r_{w}^{2}}{r^{2}} \\
& \times\left[\frac{(M+1)\left[(M-1) P_{w}+\sigma_{0}\right]}{2 M\left[(M-1) \sigma_{h}+\sigma_{0}\right]}\right]^{2 M /(M-1)}-P_{p 0}, \\
\sigma_{z}^{\prime}= & \sigma_{v}-\frac{(0.58-1.73 A)\left[(1-M) \sigma_{h}-\sigma_{0}\right]}{M+1} \frac{r_{w}^{2}}{r^{2}} \\
& \times\left[\frac{(M+1)\left[(M-1) P_{w}+\sigma_{0}\right]}{2 M\left[(M-1) \sigma_{h}+\sigma_{0}\right]}\right]^{2 M /(M-1)}-P_{p 0} .
\end{aligned}
$$

3.4. Fracturing Pressure. When the pore pressure in shallow sediment unit is equal to the external pressure of that unit, the soil is under critical condition. If the pore pressure exceeds the critical value, the effective stress in soil will become a tensile stress. The fracturing pressure is defined as the wellbore pressure when the tensile stress exceeds the tensile strength of the formation.

The boundary condition on the wellbore wall should be satisfied when fracture initiates $[37,42]$ :

$$
\left.\sigma_{\theta}^{\prime}\right|_{r=r_{w}}=-S_{t},
$$

where $S_{t}$ is the tensile strength of the formation.

According to (21), the tangential effective stress on the wellbore wall can be written as follows:

$$
\begin{aligned}
\left.\sigma_{\theta}^{\prime}\right|_{r=r_{w}}= & \frac{-(1.73 A+0.42)(M-1)}{2 M}\left(P_{w}+\frac{\sigma_{0}}{M-1}\right) \\
& +\sigma_{h}-P_{p 0} .
\end{aligned}
$$

Inserting (24) into (23), the calculation formula of fracturing pressure for shallow sediment in deep water can be got:

$$
P_{f}=\frac{2 M\left(\sigma_{h}-P_{p 0}+S t\right)}{(1.73 A+0.42)(M-1)}-\frac{\sigma_{0}}{M-1},
$$

where $P_{f}$ is the fracturing pressure.

\section{Analysis}

To research the variation rule of the fracturing pressure, we took a set of formation parameters to analyze. The parameters are as follows: $\sigma_{h}=26 \mathrm{MPa}, P_{p 0}=21 \mathrm{MPa}, C=0.2 \mathrm{MPa}, \varphi=$ $4.5^{\circ}, S_{t}=0.02 \mathrm{MPa}, E=300 \mathrm{MPa}, v=0.35$, and $A=0.7$. The relationship of the fracturing pressure and the intermediate stress coefficient " $b$ " is shown in Figure 2.

As shown in Figure 2, it is obvious that the fracturing pressure decreases nonlinearly with the increasing of coefficient " $b$." When $b=1$, the fracturing pressure decreases by approximate $23 \%$ compared with the value when $b=0$.

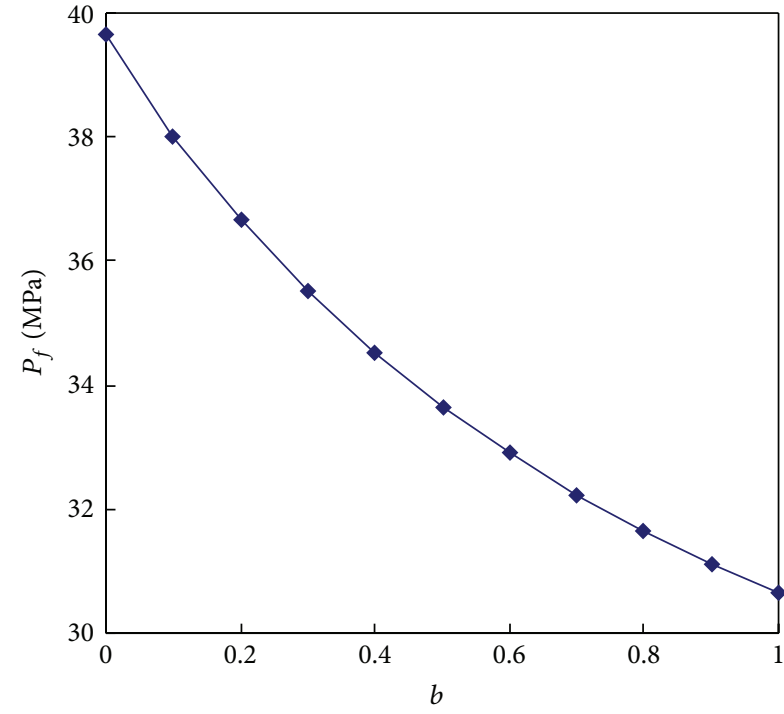

FIGURE 2: Variation of the fracturing pressure with the intermediate stress coefficient " $b$."

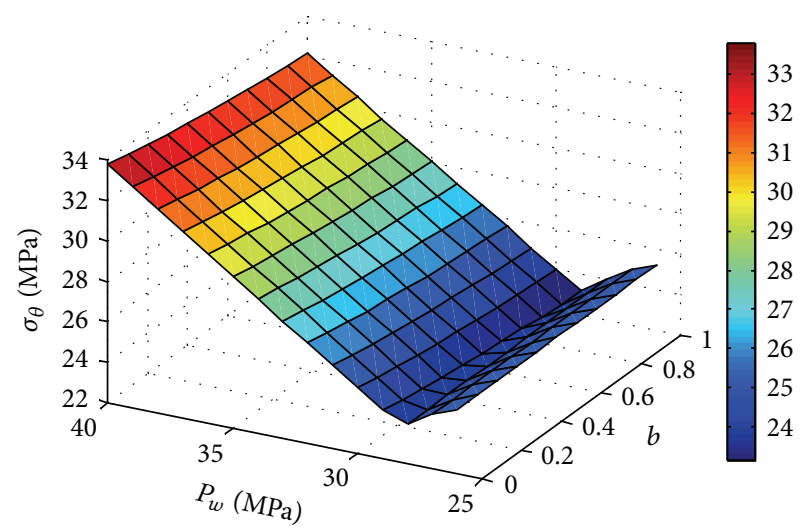

FIGURE 3: The relationship of tangential total stress on the wellbore wall with " $b$ " and $p_{w}$.

With the parameters listed above, the change rules of the tangential stress and the excess pore pressure on the wellbore wall were analyzed and shown in Figure 3 to Figure 5.

Figure 3 shows the change rule of the tangential total stress on the wellbore wall. When the wellbore pressure is less than $29 \mathrm{MPa}$, the wellbore wall is in elastic state. The tangential total stress decreases with the increasing of the wellbore pressure increasing in elastic state, but in plastic state it increases with the increasing of the wellbore pressure and decreases with the increasing of the coefficient " $b$."

Figure 4 shows the change of the excess pore pressure with the wellbore pressure and the coefficient " $b$." It reveals that higher drilling fluid density or smaller coefficient " $b$ " means a higher excess pore pressure.

Figure 5 shows the variation of tangential effective stress. It reveals that the change rule of tangential effective stress is different from that of the total stress. The tangential effective stress always decreases with the increasing of the wellbore 
TABLE 2: The calculation parameters of fracturing pressure.

\begin{tabular}{|c|c|c|c|c|c|c|c|c|}
\hline Well number & Water depth/m & Formation depth/m & $\sigma_{h} / \mathrm{MPa}$ & $P_{p 0} / \mathrm{MPa}$ & $\mathrm{C} / \mathrm{MPa}$ & $\varphi /^{\circ}$ & $\mathrm{St} / \mathrm{MPa}$ & $A$ \\
\hline A1 & 1314 & 1868 & 23.1 & 19.2 & 0.1 & 4.4 & 0.02 & 0.7 \\
\hline A2 & 1360 & 2010 & 25.3 & 21.0 & 0.1 & 4.7 & 0.02 & 0.7 \\
\hline A3 & 1432 & 1987 & 24.4 & 20.5 & 0.1 & 4.3 & 0.02 & 0.7 \\
\hline
\end{tabular}

TABLE 3: The comparison of theoretical results and LOT results.

\begin{tabular}{lccccc}
\hline$b$ & \multicolumn{3}{c}{ Theoretical results $(\mathrm{MPa})$} & & \multicolumn{2}{c}{ LOT results $(\mathrm{MPa})$} \\
$\mathrm{A}$ & $\mathrm{A} 2$ & $\mathrm{~A} 3$ & $\mathrm{~A} 2$ & \\
\hline 0 & 32.3 & 36.1 & 33.9 & & \\
0.1 & 31.0 & 34.7 & 32.5 & & \\
0.2 & 29.9 & 33.5 & 31.4 & & 28.8 \\
0.3 & 29.0 & 32.4 & 30.4 & 26.1 & 27.6 \\
0.4 & 28.2 & 31.6 & 29.6 & & \\
0.5 & 27.5 & 30.8 & 28.9 & & \\
0.6 & 26.9 & 30.2 & 28.2 & & \\
0.7 & 26.4 & 29.6 & 27.7 & & \\
0.8 & 25.9 & 29.1 & 27.2 & & \\
0.9 & 25.5 & 28.6 & 26.7 & & \\
1 & 25.1 & 28.2 & 26.3 & & \\
\hline
\end{tabular}

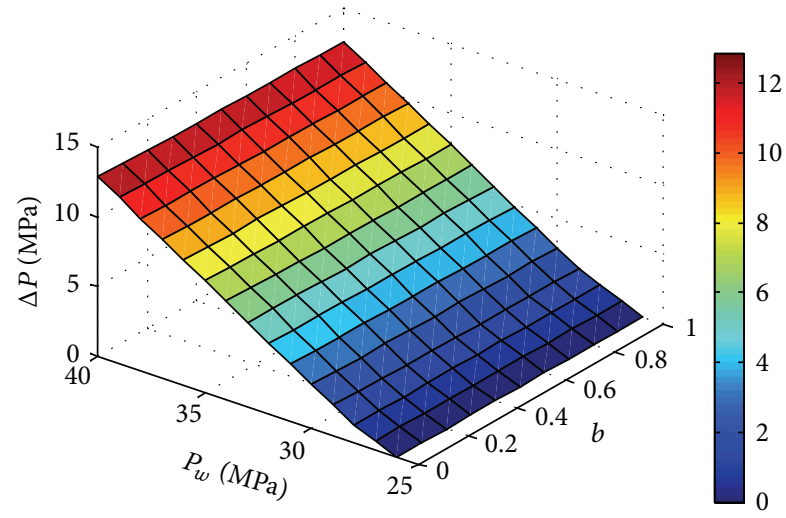

FIGURE 4: The relationship of excess pore pressure on the wellbore wall with " $b$ " and $p_{w}$.

pressure and decreases with the coefficient " $b$ " increasing. It is the influence of excess pore pressure that causes the great difference between the change rules of total stress and effective stress. The increasing rate of the excess pore pressure is higher than that of the total stress, so even though the tangential stress in plastic state increases with a wellbore pressure increasing, the effective stress decreases gradually.

\section{Case Study}

To verify the theory in this paper, the field measured results of a deep water oil field at West Africa are taken as a case study. The calculation parameters are listed in Table 2 and the calculation results and measured results are shown in Table 3. The actual measured fracturing pressure was obtained from the leak off tests (LOT).

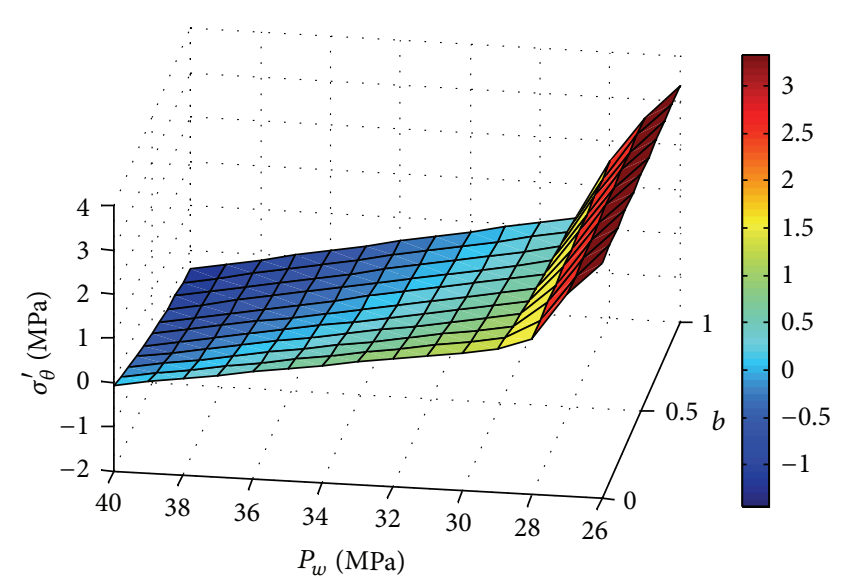

FIGURE 5: The relationship of tangential effective stress on the wellbore wall with " $b$ " and $p_{w}$.

As shown in Table 3, when $b=1$, the error of the theoretical value for well A1 compared with the measured value is $3.8 \%$, and for well A2 and well A3, the error is $2.1 \%$ and $4.7 \%$, respectively. The fracturing pressure increases with the coefficient " $b$ " decreasing. This table shows a fairly good agreement between the calculation results and the measured results, which verifies the feasibility of introducing the excess pore pressure theory into the fracturing mechanism analysis of shallow sediment in deep water, and the influence of intermediate stress should be taken into account when calculating the fracturing pressure of shallow sediment in deep water.

\section{Conclusions}

(1) The shallow sediment in deep water is unconsolidated and easily getting into plastic state, so there must be a 
plastic zone before the fracture initiates. When calculating the fracturing pressure, the stress distribution rule around the wellbore after turning into plastic state needs to be analyzed.

(2) During the drilling process, a high wellbore pressure will cause soil squeezing effect near the wellbore and result in an increase of the pore pressure, so the excess pore pressure generates. The fracturing of shallow sediment is mainly due to the generation of excess pore pressure which makes the effective stress on the wellbore wall decrease to tensile stress.

(3) The fracturing pressure of shallow sediment in deep water decreases nonlinearly with the increasing of the intermediate principle stress coefficient " $b$." In elastic state, the tangential total stress decreases with the increasing of the wellbore pressure; in plastic state, the tangential total stress increases with the increasing of the wellbore pressure and decreases with the increasing of " $b$." The excess pore pressure increases with the drilling fluid density increasing and decreases little with " $b$ " increasing. The tangential effective stress decreases with the drilling fluid density increasing and decreases with " $b$ " increasing.

(4) The agreement of the theoretical results and the measured data verifies the feasibility of the theory established in this paper. The introduction of excess pore pressure theory into wellbore stability analysis successfully explains the fracture mechanism of shallow sediment in deep water, which is an innovative progress in the theory exploration.

(5) The shallow sediment in deep water has not changed to rock, and it is under the control of saturated soil consolidation theory. In the analysis of geological mechanics problems in shallow sediments, the soil mechanics theory should be introduced into the analysis.

\section{Acknowledgments}

This paper is supported by Science Fund for Creative Research Groups of the National Natural Science Foundation of China (Grant no. 51221003), National Natural Science Foundation Project of China (Grant no. 51174219), and National Oil and Gas Major Project of China (Grant no. 2011ZX05009-005 and Grant no. 2011ZX05026-001-01).

\section{References}

[1] B. Yu, C. Yan, J. Deng, S. Liu, Q. Tan, and K. Xiao, "Evaluation and application of wellbore stability in deep water," Drilling \& Production Technology, vol. 33, no. 6, pp. 1-4, 2011.

[2] M. E. Zeynali, "Mechanical and physico-chemical aspects of wellbore stability during drilling operations," Journal of Petroleum Science and Engineering, vol. 82-83, pp. 120-124, 2012.

[3] J. Zhang, J. Lang, and W. Standifird, "Stress, porosity, and failure-dependent compressional and shear velocity ratio and its application to wellbore stability," Journal of Petroleum Science and Engineering, vol. 69, no. 3-4, pp. 193-202, 2009.
[4] S. M. Willson, S. Edwards, P. D. Heppard et al., "Wellbore stability challenges in the deep water, Gulf of Mexico: case history examples from the pompano field," in SPE Annual Technical Conference and Exhibition, Proceedings-Mile High Meeting of the Minds, pp. 1833-1842, October 2003, SPE 84266.

[5] E. B. Eaton, "Fracture gradient prediction and its application in oilfield operations," Journal of Petroleum Technology, vol. 21, no. 10, pp. 1353-1360, 1969.

[6] R. A. Anderson, D. S. Ingram, and A. M. Zanier, "Determining fracture pressure gradients from well logs," Journal of Petroleum Technology, vol. 25, pp. 1259-1268, 1973.

[7] H. Rongzun, "A model for predicting formation fracture pressure," Journal of East China Petroleum Institute, vol. 4, pp. 335347, 1984.

[8] K. Guo and P. Chang, "Study on prediction of fracturing pressure of shallow layer," Chinese Journal of Rock Mechanics and Engineering, vol. 23, no. 14, pp. 2484-2487, 2004.

[9] J. Huang, D. V. Griffiths, and S.-W. Wong, "Initiation pressure, location and orientation of hydraulic fracture," International Journal of Rock Mechanics and Mining Sciences, vol. 49, pp. 5967, 2012.

[10] B. S. Aadnøy and M. Belayneh, "Elasto-plastic fracturing model for wellbore stability using non-penetrating fluids," Journal of Petroleum Science and Engineering, vol. 45, no. 3-4, pp. 179-192, 2004.

[11] B. S. Aadnoy, "Geomechanical analysis for deep-water drilling," in Proceedings of the IADC/SPE Drilling Conference, pp. 441456, March 1998, SPE 39339.

[12] R. Chhajlani, Z. Zheng, D. Mayfield, and B. MacArthur, "Utilization of Geomechanics for Medusa Field Development, Deepwater Gulf of Mexico," in Proceedings of the SPE Annual Technical Conference and Exhibition, pp. 3821-3832, October 2002, SPE 77779.

[13] D. G. Ritter and B. Grollimund, "Wellbore stability in the deepwater Bijupira \& Salema fields, Offshore Brazil—a probabilistic approach," in Offshore Technology Conference (OTC '03), Houston, Tex, USA, May 2003, OTC 15205.

[14] S. M. Willson, S. T. Edwards, A. Crook et al., "Assuring stability in extended-reach wells-analyses, practices, and mitigations," in SPE/IADC Drilling Conference and Exhibition 2007, pp. 358371, February 2007, SPE 105405.

[15] J. Lang, S. Li, and J. Zhang, "Wellbore stability modeling and real-time surveillance for deepwater drilling to weak bedding planes and depleted reservoirs," in SPE/IADC Drilling Conference and Exhibition 2011, pp. 145-162, March 2011, SPE/IADC 139708-MS.

[16] A. K. Wojtanowicz, A. T. Bourgoyne, D. Zhou, and K. Bender, "Strength and fracture gradients for shallow marine sediments," Final Report Submitted To the U.S., Department of Interior Mineral Management Service, 2000.

[17] L. S. Rocha, P. Junqueira, and J. Roque, "Overcoming deep and ultra deepwater drilling challenges," in Offshore Technology Conference (OTC '03), Houston, Tex, USA, May 2003, OTC 15233.

[18] E. Kaarstad and B. S. Aadnoy, "Fracture model for general offshore applications," in SPE Asia Pacific Oil and Gas Conference and Exhibition 2006: Thriving on Volatility, pp. 867-872, September 2006, SPE 101178.

[19] E. Kårstad and B. S. Aadnoy, "Improved prediction of shallow sediment fracturing for offshore applications," SPE Drilling \& Completion, vol. 23, no. 2, pp. 88-92, 2008. 
[20] B. Yu, C. Yan, J. Deng et al., "Study and application of calculation model of safe drilling fluid density window: a case study of AKPO oilfield, West Africa," China Offshore Oil and Gas, vol. 24, no. 2, pp. 58-60, 2012.

[21] Z. Hu, Soil Mechanics and Environment Soil Engineering, Tongji University Press, Shanghai, China, 1997.

[22] D.-S. Jeng, B. R. Seymour, and J. Li, "A new approximation for pore pressure accumulation in marine sediment due to water waves," International Journal for Numerical and Analytical Methods in Geomechanics, vol. 31, no. 1, pp. 53-69, 2007.

[23] B. Dugan, "Fluid flow in the Keathley Canyon 151 Mini-Basin, northern Gulf of Mexico," Marine and Petroleum Geology, vol. 25, no. 9, pp. 919-923, 2008.

[24] T.-H. Kwon, K.-I. Song, and G.-C. Cho, "Destabilization of marine gas hydrate-bearing sediments induced by a hot wellbore: a numerical approach," Energy \& Fuels, vol. 24, no. 10, pp. 5493-5507, 2010.

[25] M. Yu and L. He, "A new model and theory on yield failure of materials under the complex stress state," in Mechanical Behaviour of Materials S26, M. Jono and T. Inoue, Eds., pp. 841846, Prergamon Press, Oxford, UK, 1991.

[26] V. A. Kolupaev, M. Moneke, and F. Becker, Mehraxiales Kriechen von Thermoolast2Formteilen, VDI Verlag, Darmstadt, Germany, 2005.

[27] H. Y. Liu, S. Q. Kou, P.-A. Lindqvist, and C. A. Tang, "Numerical simulation of the rock fragmentation process induced by indenters," International Journal of Rock Mechanics and Mining Sciences, vol. 39, no. 4, pp. 491-505, 2002.

[28] J. Sun and S. Wang, "Rock mechanics and rock engineering in China: developments and current state-of-the-art," International Journal of Rock Mechanics and Mining Sciences, vol. 37, no. 3, pp. 447-465, 2000.

[29] M.-H. Yu, "Advances in strength theories for materials under complex stress state in the 20th century," Applied Mechanics Reviews, vol. 55, no. 3, pp. 169-218, 2002.

[30] M.-H. Yu, Unified Strength Theory and Its Applications, Springer, Berlin, Germany, 2004.

[31] T. Ramamurthy, "Shear strength response of some geological materials in triaxial compression," International Journal of Rock Mechanics and Mining Sciences, vol. 38, no. 5, pp. 683-697, 2001.

[32] X.-N. Gong, "Some problems concerning shear strength of soil in soft clay ground," Chinese Journal of Geotechnical Engineering, vol. 33, no. 10, pp. 1596-1600, 2011.

[33] C.-G. Zhang, Q.-H. Zhang, and J.-H. Zhao, "Unified solutions of well-bore stability considering strain softening and shear dilation," Journal of the China Coal Society, vol. 34, no. 5, pp. 634-639, 2009.

[34] J. Li, M. Yu, and S. Wang, "Unified limit analysis of a wellbore under the effect of pore pressure and seepage," Journal of Mechanical Strength, vol. 23, no. 2, pp. 239-242, 2001.

[35] J. Wang, J. Zhao, L. Wang, J. Wang, and S. Sun, "Stress analysis of wellbore rock based on unified strength theory," Journal of Architecture and Civil Engineering, vol. 26, no. 3, pp. 105-109, 2009.

[36] Z. Nie, B. Xia, L. Zhou, and J. Deng, "Modeling of wellbore stability for gas drilling," Natural Gas Industry, vol. 31, no. 6, pp. 71-76, 2011.

[37] E. Fjær, R. M. Holt, P. Horsrud, A. M. Raaen, and R. Risnes, Petroleum Related Rock Mechanics, Elsevier, 2nd edition, 2008.

[38] X. Gong, Advanced Soil Mechanics, Zhejiang University Press, Zhejiang, China, 1996.
[39] A. W. Skempton, "The pore-pressure coefficients A and B," Geotechnique, vol. 4, no. 4, pp. 143-147, 1954.

[40] J. Qian and Z. Yin, Geotechnical Principles and Calculation, China Water Resource and Hydropower Press, Beijing, China, 2nd edition, 1994.

[41] D. J. Henkel, "The shear strength of saturated remolded clays," in Research Conference on Shear Strength of Cohesive Soils, pp. 533-554, ASCE, Boulder, Colo, USA, 1960.

[42] M. Chen, Y. Jin, and G. Zhang, Petroleum Related Rock Mechanics, Science Press, Beijing, China, 2008. 


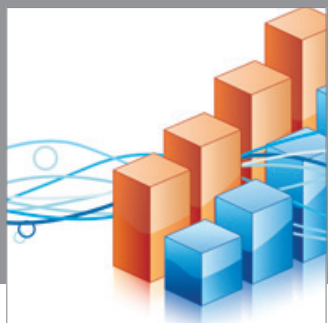

Advances in

Operations Research

mansans

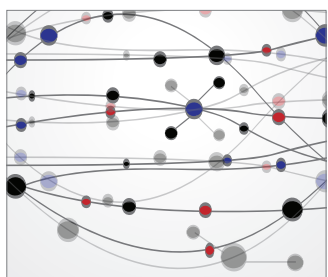

The Scientific World Journal
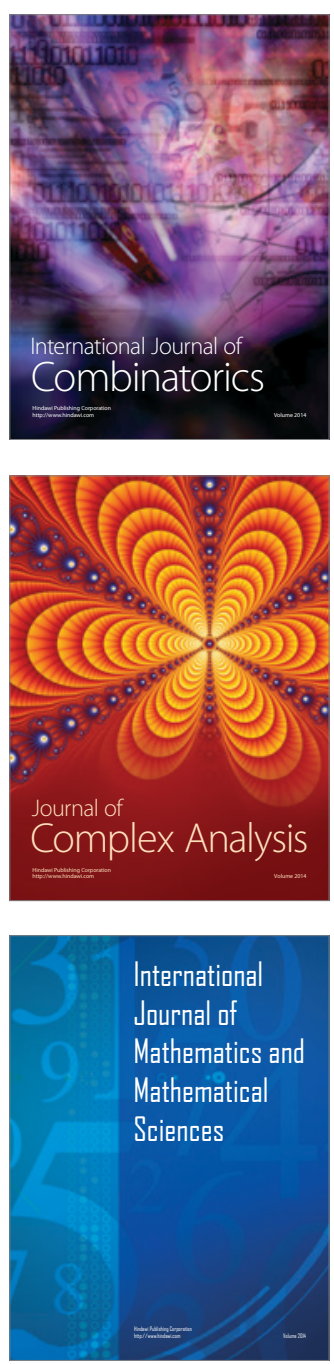
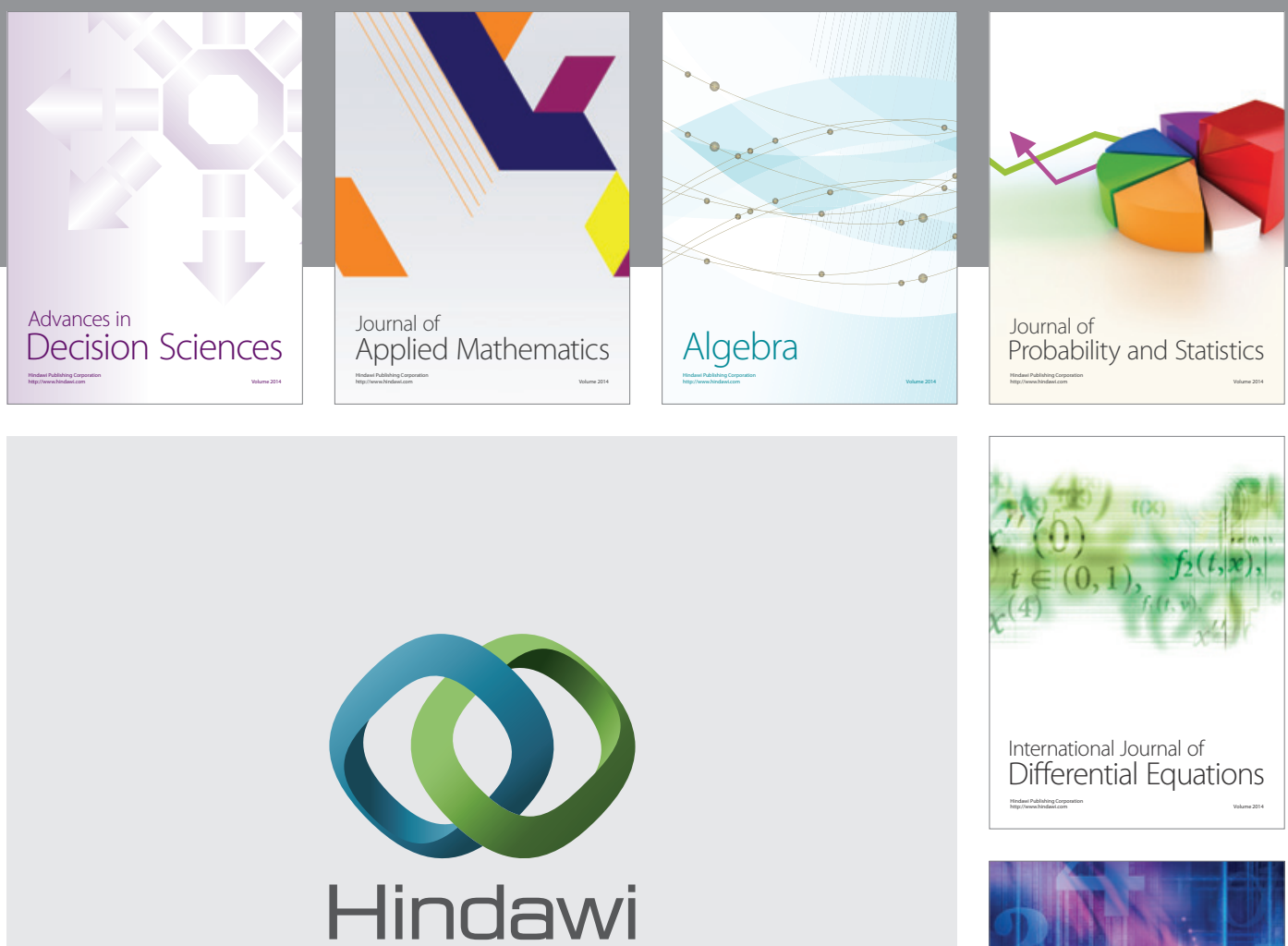

Submit your manuscripts at http://www.hindawi.com
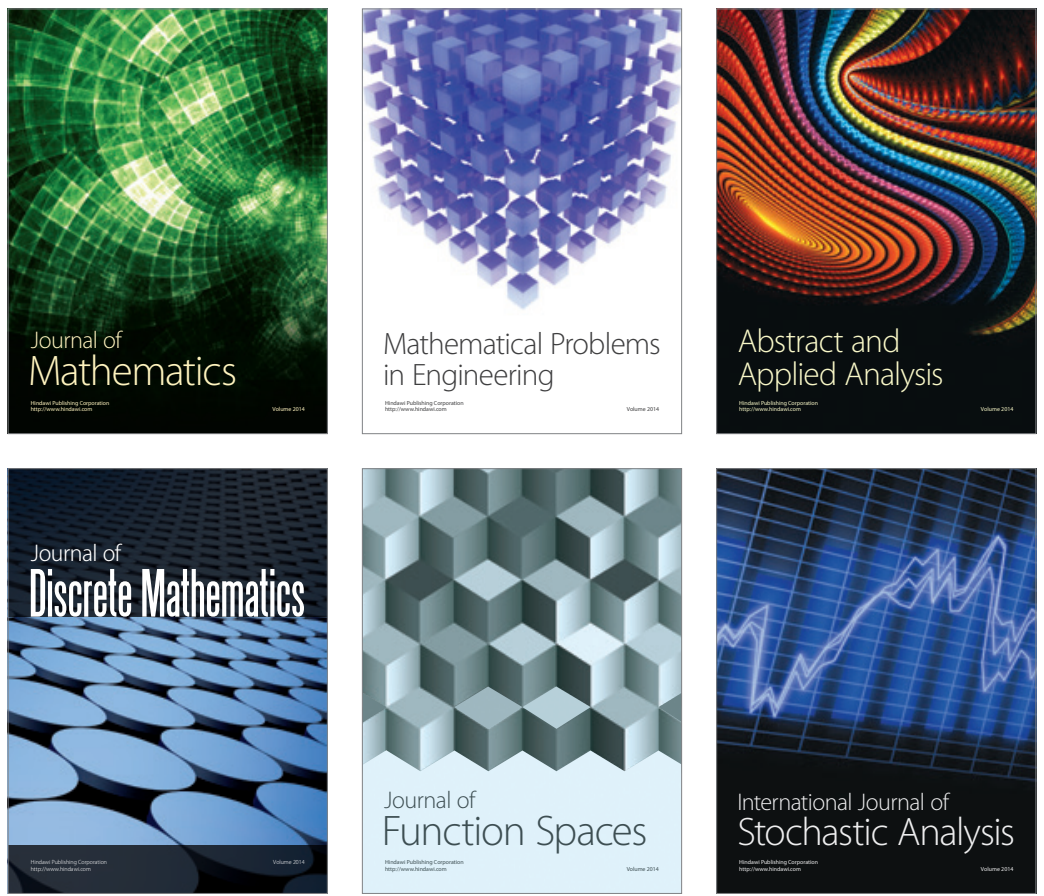

Journal of

Function Spaces

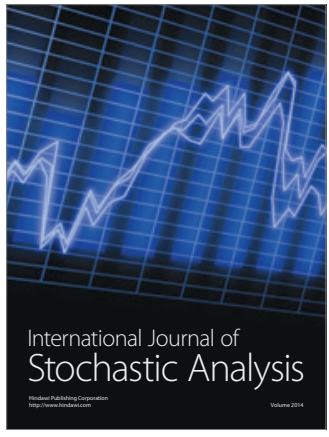

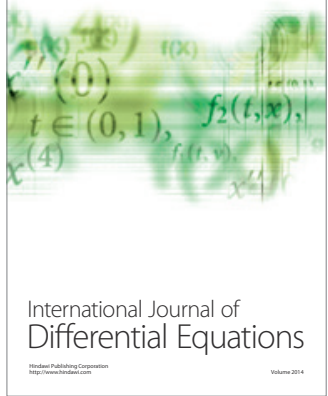
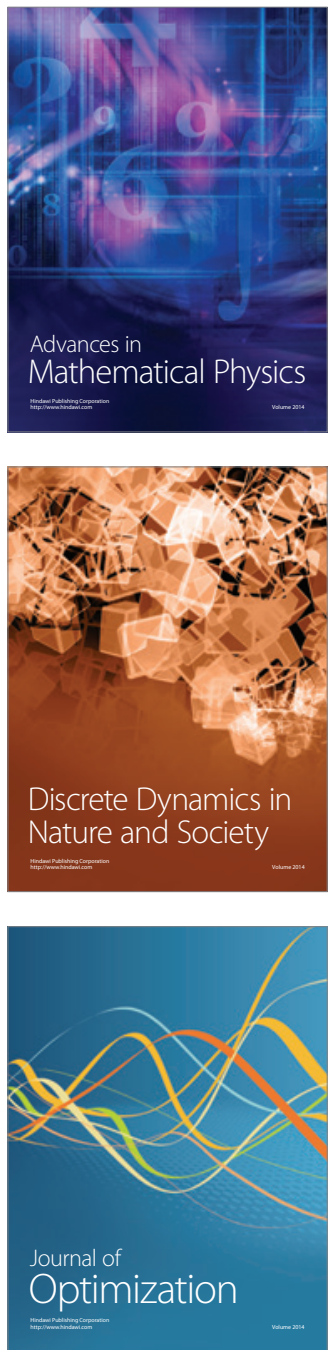